\title{
PENGARUH DOSIS SPERMA YANG DIENCERKAN DENGAN NaCI FISIOLOGIS TERHADAP FERTILITAS TELUR PADA INSEMINASI BUATAN AYAM KAMPUNG
}

\section{THE EFFECT OF SPERM DOSES DILUTED IN PHYSIOLOGICAL NACI ON EGG FERTILITY IN NATIVE CHICKEN ARTIFICIAL INSEMINATION}

\author{
Widya Asmarawati*, Kustono, Diah Tri Widayati, Sigit Bintara, dan Ismaya \\ Fakultas Peternakan, Universitas Gadjah Mada, Jl. Fauna No. 3, Bulaksumur, Yogyakarta, 55281
}

\section{INTISARI}

Penelitian ini bertujuan untuk mengetahui pengaruh dosis sperma untuk Inseminasi Buatan (IB) pada ayam kampung terhadap fertilitas telurnya. Dosis IB ini berguna untuk mengetahui perbandingan jantan dan betina yang paling efisien dalam suatu pemeliharaan. Sperma ditampung dan dicampur dari 5 ekor ayam Pelung jantan yang berumur sekitar 52 minggu. Sperma yang telah diketahui konsentrasinya kemudian dibagi menjadi 3 bagian dan masing-masing diencerkan dengan $\mathrm{NaCl}$ fisiologis sehingga diperoleh dosis akhir yaitu $25 \times 10^{6} / 0,1 \mathrm{ml}(\mathrm{dosis} 1)$; $75 \times 10^{6} / 0,1 \mathrm{ml}$ (dosis 2); dan $150 \times 10^{6} / 0,1 \mathrm{ml}$ (dosis 3). Sembilan ekor ayam kampung betina diinseminasi untuk mengetahui pengaruh dosis terhadap fertilitas telur. Ayam betina yang digunakan adalah ayam kampung yang berumur sekitar 30 minggu. Hasil penelitian menunjukkan bahwa perlakuan dosis sperma tidak berpengaruh pada fertilitas telur ayam kampung. Fertilitas telur untuk masing-masing perlakuan dosis 1, 2, dan 3 adalah 44,13 $\pm 20,84 ; 66,67 \pm 23,57$; dan $58,75 \pm 14,36 \%$. Kesimpulan dari penelitian ini adalah dosis sperma tidak berpengaruh pada fertilitas telur ayam kampung.

(Kata kunci: Ayam kampung, Dosis sperma, Inseminasi buatan)

\section{ABSTRACT}

The aim of the present experiment was to study the effect of insemination doses on eggs fertility of native chicken. The insemination doses were used to measured the most comparison efficiency of male and female in one flock. Semen was collected and pooled from 5 cockerels aged 52 weeks. Sperm was diluted with physiological NaCl and divided into 3 parts of final doses. Three treatment doses were $25 \times 10^{6} / 0.1 \mathrm{ml} ; 75 \times 10^{6} / 0.1 \mathrm{ml}$ and $150 \times 10^{6} / 0.1 \mathrm{ml}$. A total of 9 hens of native chicken aged 30 weeks used for artificial insemination with 3 treatment doses for eggs fertility trials. The result of the study indicated no significant effect of insemination doses treatment on eggs fertility. Eggs fertility for dose 1 , dose 2 and dose 3 were 44.13 \pm 20.84 ; 66.67 \pm 23.57 and $58.75 \pm 14.36 \%$. In conclusion, insemination doses have no effect to fertility of chicken eggs.

(Keyword: Native chicken, Sperm doses, Artificial insemination)

\section{Pendahuluan}

Perbandingan jumlah pejantan dan betina dalam suatu peternakan atau perusahaan pembibitan ayam yang menghasilkan final stock sangat berpengaruh pada fertilitas telur dan jumlah biaya yang dikeluarkan untuk konsumsi pakan. Perbandingan antara ayam jantan dan betina dengan perkawinan alami adalah berkisar antara 1 banding 10 (Iskandar, 2007). Efisiensi pemeliharaan dapat dilakukan jika perbandingan tersebut dapat dikecilkan dan tentunya perkawinan dengan Inseminasi Buatan (IB) menjadi solusi langkah ini. Permasalahan pemeliharaan juga muncul ketika ayam jantan yang dominan dalam suatu kandang koloni menghasilkan

\footnotetext{
* Korespondensi (corresponding author):

Telp. +62 8156895246

E-mail: widyasmarawati@gmail.com
}

sekitar $65 \%$ dari keseluruhan keturunan, hal ini berarti bahwa pejantan lain lebih jarang mengawini atau bahkan tidak sama sekali (Cheng dan Burns, 1988). Perilaku unggas jantan yang lebih suka pada satu betina yang berakibat terjadinya persaingan antar betina menjadikan banyak betina tidak terkawini (Suprijatna et al., 2005). Kejadian ini menyebabkan fertilitas telur secara kumulatif rendah.

Blanco et al. (2009) menyatakan bahwa IB pertama kali berhasil dilakukan pada burung hampir satu abad yang lalu ketika Ivanov mengawinkan ayam betina menggunakan sperma dari ductus deferens. Perkawinan dengan IB membutuhkan jumlah pejantan yang jauh lebih sedikit, tergantung dari produksi spermanya dan kebutuhan sperma oleh betina untuk mempertahankan produksi telur. Efisiensi perbandingan jumlah pejantan dan betina dengan IB akan menekan biaya produksi sehingga 
diharapkan dapat meningkatkan keuntungan peternak.

Kira-kira hanya $1 \%$ spermatozoa dari dosis IB yang akan masuk ke sperm storage tubulus (SST) di dalam utero-vaginal junction, sedangkan sisanya tertekan keluar dari vagina (Steele dan Wishart, 1996). Sejumlah sperma yang ada pada SST tersebut akan cukup untuk fertilisasi selama kurang lebih 2 minggu. Produksi sperma ayam menurut Garner dan Hafez (2000) adalah sekitar 0,2 $\mathrm{ml}$ sampai $0,5 \mathrm{ml}$ dengan rata-rata $0,25 \mathrm{ml}$ per ejakulasi. Volume sperma ayam yang sedikit tersebut harus dibuat dosis yang tepat agar sperma tidak banyak yang terbuang. Dosis IB yang selama ini dipakai berkisar antara 1:6 sampai 1: 10 (Anonimus, 1998). Perbandingan tersebut kurang menguntungkan karena dosis yang dipakai masih dapat dioptimalkan sehingga akan lebih banyak betina yang dapat diinseminasi.

Dosis IB pada ayam menggunakan sperma segar sangat bervariasi antara $70 \times 10^{6} / \mathrm{ml}$ (Cerolini et al., 1997) sampai $200 \times 10^{6} / \mathrm{ml}$ (Blesbois dan Reviers, 1992). Dosis IB pada ayam menurut Bakst

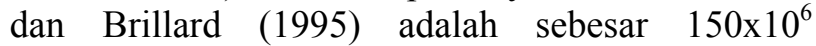
spermatozoa dengan frekuensi seminggu sekali. Castillo et al. (2010) juga melakukan uji fertilitas spermatozoa pada ayam pembibit menggunakan IB dengan interval 4 hari. Blanco et al. (2009) melakukan IB pada burung bangau dengan dosis $15 \times 10^{6}$ spermatozoa motil dengan frekuensi 3 kali atau lebih tiap minggunya. Usaha ini menghasilkan fertilitas sebesar $80 \%$. Penelitian lain oleh Gumulka dan Kapkowska (2005) menggunakan dosis $125 \times 10^{6} / 0,06 \mathrm{ml}$ dan IB dilakukan setelah 12 sampai 13 jam setelah matahari terbit. Penelitianpenelitian tersebut di atas belum ada yang mengamati secara khusus pengaruh level dosis IB yang tepat dan kaitannya dengan efisiensi pemeliharaan jumlah pejantan dalam usaha menghasilkan DOC.

Tujuan penelitian ini adalah untuk merintis usaha sosialisasi IB ayam kepada masyarakat peternak dengan dosis yang efektif dan metode yang mudah sehingga membantu dalam hal efisiensi penggunaan pejantan dan usaha peningkatan jumlah DOC yang dihasilkan. Usaha perkawinan dengan IB diharapkan dapat membantu pelaksanaan persilangan yang sudah banyak dilakukan, sehingga terjadi peningkatan populasi ayam kampung untuk dipelihara sebagai penghasil daging.

\section{Materi dan Metode}

Materi penelitian ini adalah sperma yang ditampung dari 5 ekor ayam kampung yaitu ayam Pelung jantan berumur sekitar 52 minggu. Sembilan ayam kampung betina berumur sekitar 30 minggu dibagi menjadi 3 kelompok perlakuan dosis IB. Penelitian ini berlangsung di Laboratorium Fisiologi dan Reproduksi Ternak, Fakultas Peternakan Universitas Gadjah Mada.

Penelitian ini dibagi menjadi 2 tahap yaitu tahap prapenelitian dan tahap penelitian. Prapenelitian dilakukan selama 6 minggu untuk menyesuaikan keadaan ternak dengan lingkungan, dan membiasakan ternak dengan penampungan sperma. Tahap selanjutnya adalah pelaksanaan penelitian yang meliputi penampungan sperma, pengenceran sperma, IB, pengamatan fertilitas, dan pengamatan daya tetas.

Penampungan sperma dilakukan pada pagi hari sekitar pukul 09.00 WIB oleh dua orang dengan metode Burrows dan Quinn (1937) yaitu pengurutan abdominal (Donoghue dan Wishart, 2000). Ayam dipegang dengan tangan kanan pada kaki dan diurut pada bagian punggung dari arah depan ke belakang sampai sekitar kloaka dengan tangan kiri, dan sperma yang keluar ditampung dengan tabung penampung yang diarahkan ke kloaka. Pengurutan dilakukan selama 2 sampai 3 menit untuk setiap ekor ayam jantan. Penampungan sperma dilakukan dengan 4 kali replikasi.

Sperma segar hasil penampungan segera dicampur (hasil dari semua ayam) dan diperiksa kualitasnya. Penambahan pengencer disesuaikan dengan dosis sperma yang akan digunakan. Rumus yang digunakan adalah:

$$
\mathrm{Vt}=\frac{\mathrm{VoxMxK}}{\mathrm{D}} \text { dan } \mathrm{Vp}=\mathrm{Vt}-\mathrm{Vo}
$$

\section{Keterangan:}

$\mathrm{Vt}=$ volume total pengenceran $(\mathrm{ml})$

Vo $=$ volume sperma awal $(\mathrm{ml})$

$\mathrm{M}=$ motilitas spermatozoa

$\mathrm{K}=$ konsentrasi spermatozoa $/ \mathrm{ml}$

$\mathrm{D}=$ dosis IB yang diinginkan

$\mathrm{Vp}=$ volume pengencer $(\mathrm{ml})$

Hasil perhitungan volume masing-masing pengencer yang akan digunakan kemudian dicampur dalam tabung dengan sperma yang telah dibagi sesuai jumlah perlakuan. Ada 3 perlakuan dosis IB yaitu $25 \times 10^{6} / 0,1 \mathrm{ml}$ (dosis 1$) ; 75 \times 10^{6} / 0,1$

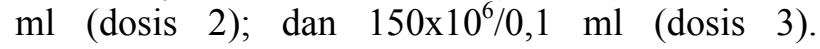
Pengencer yang digunakan adalah larutan $\mathrm{NaCl}$ fisiologis $0,85 \%$.

Ayam betina di-IB sesaat setelah sperma diencerkan. IB dilaksanakan pada sore hari sekitar pukul 14.30 dengan menggunakan sperma hasil penampungan sesaat sebelumnya. Inseminasi dilakukan dengan metode intra vaginal (sperma disuntikkan ke dalam vagina dengan kedalaman 2 
sampai $4 \mathrm{~cm}$ ). IB dilakukan dengan 4 kali replikasi dan interval 4 hari sekali untuk setiap ayam betina.

Tahapan pelaksanaan IB meliputi pembersihan kotoran yang menempel di kloaka dan sekitarnya dengan menggunakan tisu pembersih. Bagian tubuh ayam di bawah kloaka ditekan hingga terlihat saluran reproduksi (sebelah kiri) dan saluran kotoran (sebelah kanan), sperma yang sudah diencerkan disedot dengan spuit tanpa jarum sebanyak 0,1 ml kemudian dimasukkan ke dalam alat reproduksi betina. IB dengan cara yang sama dilakukan pada perlakuan dosis yang berbeda.

Telur yang digunakan sebagai telur tetas adalah telur-telur yang dihasilkan selama 15 hari sejak hari ke-2 dari IB yang pertama kali dilakukan. Telur tetas yang baik memiliki persyaratan antara lain: berbentuk oval, tidak cacat, memiliki kerabang yang tidak terlalu tebal atau tipis. Telur disimpan dahulu selama 2 sampai 4 hari pada ruangan penyimpanan sebelum dimasukkan mesin tetas. Mesin tetas yang dipakai adalah mesin tetas manual tipe C 100 dengan kapasitas 100 butir telur. Bagian dalam mesin tetas disemprot dengan desinfektan sehari sebelum telur dimasukkan mesin tetas untuk menjaga sterilitasnya. Telur tersebut disusun pada rak penampung telur dengan posisi miring kurang lebih $60^{\circ}$ dan bagian tumpul berada di atas. Telur dimasukkan secara massal dalam mesin tetas. Suhu mesin tetas diatur pada kisaran 38 sampai $39^{\circ} \mathrm{C}$ dengan kelembaban 45 sampai $60 \%$. Telur yang dimasukkan mesin tetas diberi tanda untuk memudahkan pembalikan telur supaya merata. Pembalikan telur dilakukan mulai hari ke-4 inkubasi sampai hari ke-18, yaitu minimal 3 kali dalam 24 jam. Pada hari ke-10 dilakukan candling untuk mengetahui fertilitas telur. Telur-telur tetas yang belum menetas setelah 22 hari dipecah untuk diamati fertilitasnya.

Jumlah telur infertil, fertil, dan mati dihitung untuk setiap perlakuan. Kemudian hasil yang didapat dihitung dengan rumus, sehingga dapat diketahui persentase fertilitasnya.

$$
\% \text { fertilitas }=\frac{\text { Jumlah total telur fertil tiap perlakuan }}{\text { Jumlah total telur tiap perlakuan }} \times 100
$$

Data yang diperoleh berupa kualitas sperma segar dianalisis dengan rerata dan standar deviasi. Data fertilitas telur dianalisis dengan analisis variansi dengan Rancangan Acak Lengkap pola searah (Astuti, 1980).

\section{Hasil dan Pembahasan}

\section{Karakteristik sperma segar}

Karakteristik sperma segar hasil penampungan dari 5 ekor ayam Pelung jantan dengan metode Burrows dan Quinn (1937) tersaji pada Tabel 1. Hasil penelitian menunjukkan kualitas sperma ayam Pelung memiliki rata-rata volume, warna, bau, konsistensi, $\mathrm{pH}$, motilitas, konsentrasi, viabilitas, dan abnormalitas berturut-turut adalah $0,14 \pm 0,05$, putih, spesifik, kental, $8,70 \pm 0,27$, $90,00 \pm 4,08, \quad 8,77 \pm 3,93, \quad 87,38 \pm 3,07, \quad$ dan $15,50 \pm 5,20$. Hasil pengamatan tersebut masih dalam rentangan normal sebagaimana dikemukakan oleh Etches (1996) bahwa volume sperma ayam berkisar antara 0,1 sampai 0,9 ml. Garner dan Hafez (2000); Iskandar (2007) menyatakan bahwa kualitas sperma yang baik seharusnya kental (sperma kalkun lebih kental dari sperma ayam) dan berwarna putih krem. Menurut Toelihere (1981) pH sperma ayam berkisar antara 6,3 sampai 7,8. Etches (1996) juga menyebutkan bahwa konsentrasi sperma ayam berkisar antara $3 \times 10^{9}$ sampai $8 \times 10^{9} / \mathrm{ml}$. Selanjutnya menurut Iskandar (2007) sperma ayam Pelung memiliki rata-rata viabilitas $87,75 \pm 3,37 \%$ dan ratarata mengandung spermatozoa normal $83,00 \pm 5,76 \%$, sedangkan menurut Castillo et al. (2010), rata-rata viabilitas dan morfologi normal spermatozoa ayam pembibit masing-masing sebesar $82,3 \pm 5,9 \%$ dan $92,9 \pm 4,0 \%$.

\section{Fertilitas telur}

Hasil pengamatan fertilitas telur hasil IB untuk setiap perlakuan dosis tersaji pada Tabel 2 . Hasil pengamatan persentase fertilitas telur pada Tabel 2 untuk masing-masing perlakuan dosis IB adalah tidak berbeda. Perlakuan dosis IB $25 \times 10^{6} / 0,1$ $\mathrm{ml}$ (dosis 1); $75 \times 10^{6} / 0,1 \mathrm{ml}$ (dosis 2); dan $150 \times 10^{6} / 0,1 \mathrm{ml}$ (dosis 3) masing-masing menghasilkan fertilitas sebesar 44,13 $\pm 20,84$; $66,67 \pm 23,57$; dan 58,75 $\pm 14,36 \%$. Persentase fertilitas tersebut berada di bawah rata-rata normal sebagaimana disebutkan oleh Long dan Kulkarni (2004) bahwa fertilitas ayam yang di-IB dengan sperma segar berkisar antara 62 sampai $77 \%$. Penyebabnya bisa dikarenakan dosis yang rendah sehingga jumlah spermatozoa tidak cukup untuk terjadinya fertilisasi pada beberapa telur yang saat oviposisinya berselang beberapa hari setelah waktu IB dilakukan, walaupun sebagaimana diketahui bahwa spermatozoa dapat bertahan pada sperm storage tubulus (SST) di dalam utero-vaginal junction sampai 15 hari atau lebih (Wishart, 1987; Lake, 1975 cit. Cheng, 1988). Hal serupa pernah dinyatakan oleh Wishart dan Staines (1999) bahwa hanya kurang dari $2 \%$ jumlah spermatozoa yang diinseminasikan dapat masuk ke dalam sperm storage tubulus (SST) di dalam utero-vaginal junction. Hal ini karena sebagian besar jumlah spermatozoa terdorong keluar yang disebabkan kontraksi vagina dari sejak 30 sampai 60 menit dari 
Tabel 1. Karakteristik sperma segar ayam Pelung (fresh sperm characteristic of Pelung rooster)

\begin{tabular}{ll}
\hline \hline \multicolumn{1}{c}{ Variabel (variable) } & \multicolumn{1}{c}{ Nilai (value) } \\
\hline Volume (ml) (volume (ml)) & $0,14 \pm 0,05^{*}$ \\
Warna (colour) & Putih (white) \\
Bau (odor) & Spesifik (specific) \\
Konsistensi (consistency) & Kental (viscous) \\
$\mathrm{pH}(\mathrm{pH})$ & $8,70 \pm 0,27 *$ \\
Motilitas (\%) (motility (\%)) & $90,00 \pm 4,08^{*}$ \\
Konsentrasi (x 10 $0^{9}$ spermatozoa $\left./ \mathrm{ml}\right)($ concentration) & $8,77 \pm 3,93^{*}$ \\
Viabilitas (\%) (viability (\%)) & $87,38 \pm 3,07^{*}$ \\
Abnormalitas (\%) (abnormality (\%)) & $15,50 \pm 5,20^{*}$ \\
\hline
\end{tabular}

* Rerata \pm SD $($ mean $\pm S D)$.

Tabel 2. Fertilitas telur hasil IB (egg fertility from artificial insemination)

\begin{tabular}{cc}
\hline \hline Dosis $\left(10^{6} / 0,1 \mathrm{ml}\right)\left(\right.$ doses $\left.\left(10^{6} / 0,1 \mathrm{ml}\right)\right)$ & ${\text { Fertilitas }(\%)(\text { fertility }(\%))^{\mathrm{ns}}}^{25}$ \\
75 & $44,13 \pm 20,84$ \\
150 & $66,67 \pm 23,57$ \\
\hline
\end{tabular}

${ }^{\mathrm{ns}}$ Berbeda tidak nyata (non significant).

pelaksanaan IB. Kejadian tersebut mengakibatkan spermatozoa yang dapat mencapai sperm storage tubulus (SST) di dalam infundibulum lebih sedikit lagi yaitu sekitar $0,02 \%$ dari dosis IB, padahal spermatozoa pada daerah inilah yang melakukan fertilisasi. Kurangnya jumlah spermatozoa yang masuk ke sperm storage tubulus (SST) menyebabkan sedikitnya jumlah spermatozoa yang berhasil masuk lapisan perivitelin dari ovum sehingga berdampak pada periode fertil seekor betina setelah IB (Bakst et al., 2010). Birkhead dan Brillard (2007) cit. Bakst et al. (2010) telah menyimpulkan hambatan-hambatan yang mungkin dialami oleh spermatozoa dalam mencapai ovum, yaitu: kegagalan spermatozoa mencapai dan memasuki sperm storage tubulus (SST), kegagalan spermatozoa dalam mencapai tempat fertilisasi pada infundibulum, kegagalan spermatozoa menembus lapisan perivitelin ovum serta kegagalan spermatozoa dalam membentuk pronukleus sehingga tidak terjadi syngamy.

\section{Kesimpulan}

Perlakuan berbagai dosis IB $25 \times 10^{6} / 0,1 \mathrm{ml}$; $75 \times 10^{6} / 0,1 \mathrm{ml}$; dan $150 \times 10^{6} / 0,1 \mathrm{ml}$ tidak berpengaruh pada fertilitas telur ayam kampung. Dosis IB untuk ayam kampung seharusnya lebih besar dari $150 \times 10^{6} / 0,1 \mathrm{ml}$ sehingga dapat mempertahankan fertilitas telur yang dihasilkan.

\section{Daftar Pustaka}

Anonimus. 1998. Inseminasi Buatan Pada Ayam Buras. Badan Penelitian dan Pengembangan Pertanian. Instalasi Penelitian dan Pengkajian Teknologi Pertanian. Jakarta.

Astuti, J. M. 1980. Rancangan Percobaan dan Analisis Statistik, bagian I. Bagian Pemuliaan Ternak, Fakultas Peternakan UGM, Yogyakarta.

Bakst, M. R. and J. P. Brillard. 1995. Mating and fertility. In: World Animal Science. P. Hunton (ed.). Poultry Production vol. C9 Elsevier, Amsterdam. Pp. 271-282.

Bakst, M. R., A. M. Donoghue, D. E. Yoho, J. R. Moyle, S. M. Whipple, M. J. Camp, G. Q. Liu and R. K. Bramwell. 2010. Comparison of sperm storage tubule distribution and number in 4 strains of mature broiler breeders and in Turkey Hens before and after the onset of photostimulation. J. Poult. Sci. 89: 986992.

Blanco, J. M., D. E. Wildt, U. Ho"fle, W. Voelker and A. M. Donoghue. 2009. Implementing artificial insemination as an effective tool for ex situ conservation of endangered avian species. Theriogenology 71: 200-213.

Blesbois, E. and M. de Reviers. 1992. Effect of different fractions of seminal plasma on the fertilizing ability of fowl spermatozoa stored in vitro. J. Reprod. Fert. 95: 263-268. 
Castillo, A., I. Romboli and M. Marzoni. 2010. Preliminary investigation on fertility and hatchability by the use of cryopreserved cock semen. Av. Biol. Res. 3: 127-128.

Cerolini, S., K. A. Kelso, R. C. Noble, B. K. Speake, F. Pizzi and L. G. Cavalchini. 1997. Relationship between spermatozoon lipid composition and fertility during aging of chickens. Biol. Reprod. 57: 976-980.

Cheng, K. M. and J. T. Burns. 1988. Dominance relationship and mating behaviour of domestic cocks - a model to study mateguarding and sperm competitions in birds. The Condor 90: 697-704.

Darwati, S. 2000. Produktivitas ayam kampung, Pelung dan resiprokalnya. Media Peternakan 23: 32-35.

Donoghue, A. M. and G. J. Wishart. 2000. Storage of poultry semen. Anim. Reprod. Sci. 62: 213-232.

El Sabry, M. I. and B. Tzschentke. 2010. Influence of short-term warm stimulation during the last 4 days of incubation time on body temperature and oxygen consumption in broiler and layer embryos. Av. Biol. Res. 3: 129-130.

Etches, R. J. 1996. Reproduction in Poultry. Cambridge University Press.

Garner, D. L. and E. S. E. Hafez. 2000. Spermatozoa and Seminal Plasma. In: Reproduction in Farm Animals $7^{\text {th }}$ ed. E. S. E. Hafez (ed.). Lea \& Febiger, Philadelphia. Pp: 96-125.
Iskandar, S. 2007. Tata Laksana Pemeliharaan Ayam Lokal. Balai Penelitian Ternak Ciawi. Bogor.

Long, J. A. and G. Kulkarni. 2004. An effective method for improving the fertility of glycerol-exposed poultry semen. J. Poult. Sci. 83: 1594-1601.

Peters, S. O., O. D. Shoyebo, B. M. Ilori, M. O. Ozoje, C. O. N. Ikeobi and O. A. Adebambo. 2008. Semen quality traits of seven strain of chicken raised in humid tropics. International J. Poult. Sci. 7: 949-953.

Steele, M. G. and G. J. Wishart. 1996. Demonstration that the removal of sialic acid from the surface of chicken spermatozoa impedes their transvaginal migration. Theriogenology 46: 1037-1044.

Suprijatna, E., U. Atmomarsono, dan R. Kartasudjana. 2005. Ilmu Dasar Ternak Unggas. Penebar Swadaya, Jakarta.

Tajima, A., E. F. Graham and D. M. Hawkins. 1989. Estimation of the relative fertilizing ability of frozen chicken spermatozoa using a heterospermic competition method. J. Reprod. Fert. 85: 1-5.

Toelihere, M. R. 1981. Inseminasi Buatan pada Ternak. Penerbit Angkasa, Bandung.

Wishart, G. J. and H. J. Staines. 1999. Measuring sperm: Egg interaction to assess breeding efficiency in chickens and Turkeys. Poult. Sci. 78: 428-436. 